\title{
FINE NEEDLE ASPIRATION CYTOLOGY IS A DIAGNOSTIC TOOL IN THE THYROID LESION
}

\author{
Mani Krishna ${ }^{1}, M^{2} j^{2}{ }^{2}$ \\ ${ }^{1}$ Associate Professor, Department of Pathology, UP Rural Institute of Medical Sciences and Research, Saifai, Etawah, Uttar Pradesh. \\ ${ }^{2}$ Consultant, Zonal Hospital, Dharamshala, Himachal Pradesh.
}

\section{ABSTRACT}

Thyroid nodules the main indication for FNAC, and the goal of this diagnostic procedure is to detect thyroid neoplasm for surgical resection and to identify non-neoplastic lesions that may be managed conservatively.

\section{MATERIAL AND METHOD}

Three hundred and fourteen patients with thyroid nodules diagnosed on physical examination underwent fine-needle aspiration with 23 -gauge needle and $10 \mathrm{ml}$ syringe. FNAC results were classified into non-neoplastic lesion and neoplastic lesion for diagnosis.

\section{RESULT AND ANALYSIS}

We included 314 cases; 37 were male and 277 were female with female-to-male ratio of 7.48:1. The age ranged from 8 to 87 years with a median age of 47.5 years. Maximum number of patients were found in age group of 41-50 years). In the present study we found 285(90.76\%) non-neoplastic lesion and 29(9.23\%) neoplastic lesions. Out of 285 non-neoplastic lesion, most commonly encountered were colloid goiter 178(56.68\%) and second most common thyroiditis $100(31.84 \%)$. Out of 314,29(9.23\%) neoplastic lesions, most commonly encountered neoplasm were papillary carcinoma $14(4.45 \%)$ followed by $9(2.86 \%)$ follicular neoplasm, Hurthle cell neoplasm 2(0.63\%), medullary carcinoma 4(1.27\%).

\section{AIMS AND OBJECTIVES}

- To study the distribution of various thyroid lesions among the age and sex groups.

- To study the cytomorphological, clinical and biochemical correlation.

\section{CONCLUSION}

Clinical features and serum findings when used alone to diagnose thyroid lesion, diagnosis will be missed in many cases.

\section{KEYWORDS}

Thyroid swelling, Goitre, Thyroiditis, Neoplasm.

HOW TO CITE THIS ARTICLE: Mani Krishna, Manju. "Fine Needle Aspiration Cytology is a Diagnostic Tool in the Thyroid Lesion.” Journal of Evolution of Medical and Dental Sciences 2015; Vol. 4, Issue 97, December 03; Page: 16232-16235, DOI: $10.14260 /$ jemds/2015/2390

\section{INTRODUCTION}

Thyroid nodular lesions are a common clinical problem. During the last two decades, FNAC has emerged as the most reliable and cost effective method in the diagnosis and management of clinically important thyroid disorders. Thyroid nodules are very frequent and it is estimated that $4 \%-7 \%$ of adults have palpable enlargement of thyroid and ten times more have impalpable nodules. ${ }^{1,2}$ Thyroid nodules are more frequent among females, elderly people, history of irradiation to the head and neck and a diet containing high amount of goitrogenes. ${ }^{1}$ Most of the thyroid nodules are benign and fewer than $5 \%$ of them are actually malignant. 2,3 Thyroid nodules, the main indication for FNA and the goal of this diagnostic procedure is to detect thyroid neoplasm for surgical resection and to identify non-neoplastic lesions that may be managed conservatively. ${ }^{4}$ Depending on personal preferences, FNA of a thyroid nodule may be performed either with or without a syringe. ${ }^{5}$

Financial or Other, Competing Interest: None.

Submission 06-11-2015, Peer Review 07-11-2015,

Acceptance 26-11-2015, Published 02-12-2015.

Corresponding Author:

Dr. Mani Krishna,

Department of Pathology,

UP Rural Institute of Medical Sciences \& Research,

Saifai, Etawah

Uttar Pradesh.

E-mail:drmanikrishna@gmail.com

DOI:10.14260/jemds/2015/2390
The gland is then carefully examined by palpation. If a residual nodule is found, it should be aspirated. Since the thyroid is rich in capillary blood vessels, the needle aspirate usually contains a large amount of peripheral blood that may be using the FNA technique without aspiration. ${ }^{5}$

\section{MATERIALS AND METHODS}

This is a study of 314 cases of thyroid lesions reported by Pathology Department in Tertiary Care Hospital, Kangra. Clinical data including age, sex, character of swelling were included. Four hundred and thirteen patients with thyroid nodules diagnosed on physical examination underwent fineneedle aspiration with 23 -gauge needle and $10 \mathrm{ml}$ syringe. For every patient more than one aspiration were used. The aspirated contents of the needle were expelled onto glass slides and smear for fixation in $95 \%$ alcohol and air dried smear was prepared. Smears were stained by Hematoxyline and Eosine and Giemsa methods. FNAC results were classified into non-neoplastic lesion and neoplastic lesion for diagnosis. Smears classified as non-neoplastic included adenomatous (Colloid) nodule and thyroiditis. The neoplastic included follicular neoplasm, Hurthle cell neoplasm, papillary carcinoma and medullary carcinoma.

\section{AIMS AND OBJECTIVES}

- To study the distribution of various thyroid lesions among the age and sex groups.

- To study the aim to determine the cytological pattern of thyroid lesions in addition to the utility of FNAC as an 
initial diagnostic method in the investigation of thyroid swelling.

- To study the cytomorphological, clinical and biochemical correlation.

\section{RESULT AND ANALYSIS}

A total of 325 patients with midline neck swelling was analysed. Out of them, 314 thyroid swelling and rest 11 were excluded due to thyroglossal cyst. We included 314 cases; 37 were male and 277 were female with female-to-male ratio of $7.48: 1$. The age ranged from 8 to 87 years with a median age of 47.5 years. The youngest was a child aged 8 years diagnosed as thyroiditis. Maximum numbers of patients were found in age group of 41-50 years. Nodular lesion being the commonest presentation.

Duration of swelling ranges from months to years. Most of the patients in this study gives history of $>2.5$ years of complaint. Distribution of cases according to site of involvement shows right lobe involvement, is more than left lobe. This study number of cases with right lobe involvement was $170(54.14 \%)$, left lobe involvement in $76(24.20 \%)$ cases, bilateral lobe involvement in $48(15.28 \%)$ cases, midline $20(6.36 \%)$. In the present study, we found $285(90.76 \%)$ nonneoplastic lesion and 29(9.23\%) neoplastic lesions. Nonneoplastic lesions included are Goitre 178(56.68\%), Adenomatoid goitre $7(2.22 \%)$ and thyroiditis $100(31.84 \%)$. Neoplastic lesion included are Follicular neoplasm 9(2.86\%), Hurthle cell neoplasm 2(0.63\%), Medullary carcinoma $4(1.27 \%)$ and Papillary cell carcinoma $14(4.45 \%)$. In the present study out of 314 cases of different thyroid lesions, thyroid profile was available in 150 cases.

Out of these, 142 non-neoplastic cases and 8 neoplastic cases were available. Out of 314,285 non-neoplastic lesion most commonly encountered were colloid goitre $178(56.68 \%)$. All the patients had a history of goitre. Nodular swellings were more common than diffuse swelling. Out of $178(56.68 \%)$ colloid goitre hormonal status was available in 80 cases; $9(11.25 \%)$ cases were euthyroid; $26(32.5 \%)$ cases were hyperthyroid; $45(56.25 \%)$ cases were hypothyroid.

Out of 285 non-neoplastic lesions, adenomatoid goitre was $7(2.22 \%)$. Out of 7 adenomatoid goitre, hormonal analysis was available in 2 cases, 1 were euthyroid and 1 hypothyroid.

We included 100 cases of thyroiditis; 6 cases were male and 94 were female. The age ranged from 8 to 65 years with a median age of 36.5 years. Maximum numbers of patients were found in age group of 41-50 with female preponderance in each group of thyroiditis; 100 cases of thyroiditis have been evaluated on the basis of cytomorphological criteria and clinical findings of patients. All the patients had a history of goiter; 69 patient had diffuse swelling and 31 had nodular swelling. Out of 100 cases of thyroiditis, Hashimoto's thyroiditis $72(\%)$, Lymphocytic thyroiditis $27(\%)$, de Quervain's thyroiditis 1(\%). Sixty patients had estimation of thyroid profiles and thyroid antibodies, which will establish 10 euthyroidism, 2 hyperthyroidism and 48 hypothyroidism. The serum TPO antibody titers were elevated in 58 patients. Two patients had normal titer. Biochemically hypothyroidism is more frequently evaluated with Hashimoto's disease. On the other hand, hyperthyroidism was observed in most other types of thyroiditis.

Out of $314,29(9.23 \%)$ neoplastic lesions, most commonly encountered neoplasm were papillary carcinoma $14(4.45 \%)$ followed by $9(2.86 \%)$ follicular neoplasm, Hurthle cell neoplasm $2(0.63 \%)$, medullary carcinoma $4(1.27 \%)$. Malignant neoplasm was 18(5.73\%); 28 had nodular swelling and 1 patient had diffuse swelling in the neoplastic lesion. In case of neoplastic lesions out of 29 cases 8 had hormonal analysis, 3 euthyroid, 3 hypothyroid and 2 hyperthyroid.

Fourteen (4.45\%) cases of papillary carcinoma were diagnosed. Two cases had cystic changes and aspiration was repeated. Thick colloid was present in two cases. Two cases with increased levels of thyroid hormone did not show the presence of fire flares.

One $(0.31 \%)$ case was in $<10$ years age group, of them were thyroiditis $1(0.31 \%) ; 32(10.19 \%)$ cases were in $11-20$ years age groups, of them colloid goitre were 18(5.73\%); thyroiditis were $12(3.82 \%)$, papillary carcinoma $2(0.63 \%)$; $68(21.65 \%)$ cases were in $21-30$ years age group, of them colloid goitre were $38(12.10 \%)$, adenomatoid goitre $2(0.63 \%)$, thyroiditis were $22(7.00 \%)$, follicular neoplasm $3(0.95 \%)$, papillary carcinoma $1(0.31 \%)$ and medullary carcinoma $1(0.31 \%) ; 67(21.33 \%)$ cases were in $31-40$ years age groups, of them colloid goitre were $34(10.82 \%)$, adenomatoid goitre $2(0.63 \%)$, thyroiditis were $23(7.32 \%)$, follicular neoplasm $2(0.63 \%)$, papillary carcinoma $4(1.27 \%)$ and medullary carcinoma $2(0.63 \%) ; 76(24.20 \%)$ cases were in 41-50 years age groups, of them maximum colloid goitre were $42(13.37 \%)$, adenomatoid goitre $1(0.31 \%)$, thyroiditis were $29(9.23 \%)$, follicular neoplasm $1(0.31 \%)$, papillary carcinoma $2(0.63 \%) ; 36(11.46 \%)$ cases were in 51-60 years age groups, of them colloid goitre were $27(8.59 \%)$, thyroiditis were $7(2.22 \%)$, follicular neoplasm $1(0.31 \%)$ and papillary carcinoma $1(0.31 \%) ; 23(7.32 \%)$ cases were in $61-70$ years age groups, of them colloid goitre were $11(3.50 \%)$, adenomatoid goitre $2(0.63 \%)$, thyroiditis were $6(1.91 \%)$, papillary carcinoma $3(0.95 \%)$ and medullary carcinoma $1(0.31 \%) ; 9(2.86 \%)$ cases were in $71-80$ years age groups, of them colloid goitre were $7(2.22 \%)$, follicular neoplasm $1(0.31 \%)$ and papillary carcinoma $1(0.31 \%) ; 2(0.63 \%)$ cases were in 81-90 years age groups, of them colloid goitre were $1(0.31 \%)$, follicular neoplasm $1(0.31 \%)$.

\begin{tabular}{|c|c|c|c|c|}
\hline Age & Male & Female & Total & \% \\
\hline$<10$ & 0 & 1 & 1 & 0.31 \\
\hline $10-20$ & 4 & 28 & 32 & 10.19 \\
\hline $21-30$ & 3 & 65 & 68 & 21.65 \\
\hline $31-40$ & 4 & 63 & 67 & 21.33 \\
\hline $41-50$ & 11 & 65 & 76 & 24.20 \\
\hline $51-60$ & 10 & 26 & 36 & 11.46 \\
\hline $61-70$ & 4 & 19 & 23 & 7.32 \\
\hline $71-80$ & 1 & 8 & 9 & 2.86 \\
\hline $81-90$ & 0 & 2 & 2 & 0.63 \\
\hline $91-100$ & 0 & 0 & 0 & 0 \\
\hline Total & $\mathbf{3 7}$ & $\mathbf{2 7 7}$ & $\mathbf{3 1 4}$ & $\mathbf{1 0 0}$ \\
\hline \multicolumn{6}{|c}{ Table 1: Age and Sex Distribution } \\
\hline
\end{tabular}




\begin{tabular}{|c|c|c|c|c|c|c|c|c|c|c|c|}
\hline Age & Male & Female & Goiter & $\begin{array}{c}\text { Adenom } \\
\text { atoid } \\
\text { Nodule }\end{array}$ & $\begin{array}{l}\text { Thyroid- } \\
\text { itis }\end{array}$ & $\begin{array}{l}\text { Hurthel } \\
\text { Cell } \\
\text { Neoplasm }\end{array}$ & $\begin{array}{l}\text { Follicular } \\
\text { Neoplasm }\end{array}$ & \begin{tabular}{|c|} 
Papillary \\
Carcinoma
\end{tabular} & $\begin{array}{l}\text { Medullary } \\
\text { Carcinoma }\end{array}$ & Total & $\%$ \\
\hline$<10$ & 0 & 1 & 0 & 0 & 1 & 0 & 0 & 0 & 0 & 1 & 0.31 \\
\hline $11-20$ & 4 & 28 & 18 & 0 & 12 & 0 & 0 & 2 & 0 & 32 & 10.19 \\
\hline $21-30$ & 3 & 65 & 38 & 2 & 22 & 0 & 3 & 1 & 1 & 68 & 21.65 \\
\hline $31-40$ & 4 & 63 & 34 & 2 & 23 & 0 & 2 & 4 & 2 & 67 & 21.33 \\
\hline $41-50$ & 11 & 65 & 42 & 1 & 29 & 2 & 1 & 2 & 0 & 76 & 24.20 \\
\hline $51-60$ & 10 & 26 & 27 & 0 & 7 & 0 & 1 & 1 & 0 & 36 & 11.46 \\
\hline $61-70$ & 4 & 19 & 11 & 2 & 6 & 0 & 0 & 3 & 1 & 23 & 7.32 \\
\hline $71-80$ & 1 & 8 & 7 & 0 & 0 & 0 & 1 & 1 & 0 & 9 & 2.86 \\
\hline $81-90$ & 0 & 2 & 1 & 0 & 0 & 0 & 1 & 0 & 0 & 2 & 0.63 \\
\hline $\begin{array}{l}91- \\
100\end{array}$ & 0 & 0 & 0 & 0 & 0 & 0 & 0 & 0 & 0 & 0 & 0 \\
\hline Total & 37 & 277 & $178(56.68 \%)$ & $7(2.22 \%)$ & $100(31.84 \%)$ & $2(0.63 \%)$ & $9(2.86 \%)$ & $14(4.45 \%)$ & $4(1.27 \%)$ & 314 & 100 \\
\hline \multicolumn{12}{|c|}{ Table 2: Distribution of Type of Thyroid Lesions } \\
\hline
\end{tabular}

\begin{tabular}{|c|c|c|c|c|c|c|}
\hline Age & Male & Female & $\begin{array}{c}\text { Hasimoto } \\
\text { Thyroiditis }\end{array}$ & $\begin{array}{l}\text { Lymphocytic } \\
\text { Thyroiditis }\end{array}$ & $\begin{array}{c}\text { de Quervain's } \\
\text { Thyroiditis }\end{array}$ & Total \\
\hline$<10$ & 0 & 1 & 1 & 0 & 0 & 1 \\
\hline $10-20$ & 1 & 10 & 8 & 3 & 0 & 11 \\
\hline $21-30$ & 1 & 24 & 20 & 5 & 0 & 25 \\
\hline $31-40$ & 0 & 23 & 13 & 9 & 1 & 23 \\
\hline $41-50$ & 3 & 25 & 20 & 8 & 0 & 28 \\
\hline $51-60$ & 1 & 6 & 5 & 2 & 0 & 7 \\
\hline $61-70$ & 0 & 5 & 5 & 0 & 0 & 5 \\
\hline $71-80$ & 0 & 0 & 0 & 0 & 0 & 0 \\
\hline $81-90$ & 0 & 0 & 0 & 0 & 0 & 0 \\
\hline 91-100 & 0 & 0 & 0 & 0 & 0 & 0 \\
\hline Total & $6(\%)$ & $94(\%)$ & $72(\%)$ & $27(\%)$ & $1(\%)$ & 100 \\
\hline \multicolumn{7}{|c|}{ Table 3: Age Distribution and Type of Thyroiditis } \\
\hline
\end{tabular}

\section{DISCUSSION}

In our study, all patients $100 \%$ had swelling over the neck. Similar observation was done by SM Nazmul Huque et al. (2012). ${ }^{6}$

Three hundred and fourteen patients found that thyroid swelling was the most common presentation in all cases $100 \%$. It was observed that most of the swelling were in right lobe $170(54.14 \%)$ followed by left lobe $76(24.20 \%)$ cases, bilateral lobe $48(15.28 \%)$ cases and $20(6.36 \%)$ were in the midline clinically. Similar observations were done by Irfan Khan et al. (2014). ${ }^{7}$ On 110 patients where 92 had swelling on right side and 18 had swelling on left side. It is also approximately similar to observations done by Sabu N. Satihal et al. (2014). ${ }^{8}$

Female-to-male ratio of 7.48:1 has been observed in present study similar to other studies. $9,10,11,12$

In the present study distribution of neoplastic and nonneoplastic cases were $9.23 \%$ and $90.76 \%$ respectively, which was similar to studies done by Ritica Choudhary, Zulfikar Ahmed, Umaru N. ${ }^{13}$ S. Chandanwale et al. ${ }^{14}$ and Junu Devil, Naima Aziz. 15

In a study by S. Chandanwale et al., a study of 150 cases from Pune showed colloid nodular goitre to be the commonest lesion constituting $65.3 \%$ of the total lesion and thyroiditis was seen in $12.6 \%$ of cases, whereas in our study colloid goitre was the commonest seen in $56.68 \%$ of cases and increase in incidence in thyroiditis $31.84 \%$.

In those cases where adequate aspirate was not obtained by non-aspiration technique, then negative suction was given with a syringe and aspiration was done. This was usually needed in cases of Hashimoto's thyroiditis. This can be explained due to the solidification of the thyroid tissue by the dense lymphocytic infiltration and reduced vascularity when compared to the other thyroid lesions. ${ }^{16}$

Inadequate sampling is seen with sclerotic calcified nodules, nodules with cystic degeneration and calcified nodules. ${ }^{17,18}$

Solitary enlargement is seen in the thyroid cyst, neoplasm and sometimes in nodular goitre. Diffuse enlargement is seen in Hashmoto's thyroiditis and colloid goitre. On palpation, cases of Hashmoto's thyroiditis were more firm in consistency when compared to other types of thyroid enlargements. Thyroiditis was the second most common lesion encountered in our study constituting 100 $(31.84 \%)$ cases, more frequently seen in $41-50$ years age group and occurs in the span of 8-65 years age. ${ }^{14}$

The natural history of chronic lymphocytic thyroiditis and Hashimoto's thyroiditis were slow progression to hypothyroidism. ${ }^{19}$ Our study show majority of cases of lymphocytic thyroiditis and Hashimoto's thyroiditis were euthyroid and hypothyroid, which is similar to other study. ${ }^{19}$ RN Baruah et al. FNAC is used to differentiate neoplastic from non-neoplastic lesions. The non-neoplastic lesion, specially Hashimoto's thyroiditis can be treated medically, hence excluded from undergoing surgery and reduce the number of thyroid surgeries. ${ }^{20}$ Bhatta et al., 6.75\% malignancy was seen in study of Chandanwale et al. and our study showed $5.73 \% .(18)$ of malignancy, $4(1.27 \%)$ were medullary carcinoma and $14(4.45 \%)$ were papillary carcinoma Papillary carcinoma of thyroid is the most commonly encountered neoplasm in our study, which is similar to studies done by Chandanwale et al., Tabaqchali et al. and Laxhmi et al.14,21,22 
Laxhmi et al. show 10 (3.98\%) cases were classified under neoplastic category, $9(2.78 \%)$ were reported as papillary carcinoma of thyroid.

The patients are grouped into three states based on clinical symptoms: euthyroid, hyperthyroid and hypothyroid. Hormonal status was known in only $150(47.77 \%)$ cases out of 314 cases in the present study.

A $15.33 \%$ cases were biochemically euthyroid. Only $20 \%$ had hyperthyroid and these patients were of goitre, thyroiditis and neoplasm; $64.66 \%$ patients had hypothyroid. Hypothyroid were seen in colloid goitre, Hashimoto's thyroiditis and neoplasm. This is in concordance with the study by Biogen et al. ${ }^{23}$

The incidence of thyroid lesion is increasing significantly nowadays. Many a times differentiation between physiological, inflammatory, autoimmune, hyperfunctioning and hypofunctioning of thyroid gland, benign and malignant tumor poses diagnostic difficulty. Fine needle aspiration cytology with clinical correlation along with thyroid function tests are done in relevant cases. Final diagnosis requires morphological examination of the lesions. Fine needle aspiration cytology is widely accepted and has become the cornerstone in evaluation of the thyroid lesion and unnecessary surgery can be avoided.

Therefore, fine needle aspiration cytology should be adopted as an initial investigation of thyroid lesion in all Tertiary Hospitals. ${ }^{24}$ Basharat R.

Thyroid enlargement, whether diffuse or in the form of a nodule leads to a battery of investigation, mainly to rule out the possibility of a neoplasm or thyroiditis.

Fine needle aspiration cytology is usually the first line of investigation and other investigation like thyroid function test and antibody levels are done subsequently with an aim to select the patients who require surgery and those that can be managed conservatively. ${ }^{25,26}$

\section{CONCLUSION}

Clinical features and serum findings when used alone to diagnose thyroid lesion diagnosis will be missed in many cases.

\section{REFERENCES}

1. Faquin WC. "Aspiration of the thyroid," in Atlas of Diagnostic Cytopathology, Atkinson BF, Ed., pp. 460-470, Saunders, 2004

2. Geisin KR, Stanley MW, Raab SS, Silverman JF, and Abati A. Modern Cytopathology, Churchill Livingstone, 2004.

3. Yeung MJ and Serpell JW. "Management of the solitary thyroid nodule." Oncologist 2008;13(2):105-112.

4. Papanicolaou Society of Cytopathology Task Force on Standard of Practice (Suen KC, Chair): Guidelines of the Papanicolaou Society of Cytopathology for the examination of fine needle aspiration specimens from thyroid nodules. Mod Pathol 1996;9:710-715.

5. Nguyen GK, Ginsberg J, Crockford PM: Fine-needle aspiration biopsy cytology of the thyroid. Its value and limitations in the diagnosis and management of solitary thyroid nodules. Pathol Annu 1991;25(1):63-91.

6. Nazmul Huque SM, Mohammad Idrish Ali. Histopathological pattern of malignancy in solitary thyroid nodule. Bangladesh J Otorhinolaryngol 2012;18(1):5-10.

7. Irfan Khan, Mohsin ul Rasool. Clinical presentation of various thyroid lesions in a study population attending a teaching hospital in North India. Int J Adv Med 2014;1(2):145-148.
8. Sabu N. Satihal Eranna R. Palled. A Study of Various Clinical Presentation of Solitary Thyroid Nodule at Tertiary Care Center; MedPulse - International Medical Journal 2014;1(1):30-32.

9. Sukant Garg, Uma Handa, Harsh Mohan, Nitin Nagarkar. "Role of fine needle aspiration cytology in diagnosis and management of thyroid lesion: A study on 434 patient." Journal of Cytology 2008;25(1):13-17.

10. Neelam Sood and Jitendra Singh Nigam. "Correlation of Fine Needle Aspiration Cytology Findings with Thyroid Function Test in Cases of Lymphocytic Thyroiditis." Journal of Thyroid Research Volume 2014.

11. Gayathri BN, Kalyani R, Harendra Kumar ML, Krishna Prasad K. "Fine needle aspiration cytology of Hashimoto's thyroiditis- a diagnostic pitfall with review of literature." Journal of Cytology 2011;28(4):210-213.

12. Cibas ES. Thyroid in Cytology: Diagnostic Principles and Clinical correlates. Cibas ES and Ducatman BS. Saunders, an imprint of Elsivier, Philadelphia, PA, USA. 2009;3rd Eds.:264-265.

13. Ritica Chaudhary, Zulfikar Ahmed, Umaru N. "A correlative study of FNAC thyroid with thyroid hormone profile." Journal of Evolution of Medical and Dental Science 2014;3(6):1474-1480.

14. Chandanwale $S$, et al. Clinicopathological correlation of thyroid nodules. Int J Pharm Biomed 2012;97-102.

15. Junu Devil, Naima Aziz. Cytomorphological Evaluation and Thyroid Function Test (Tft) Analysis in Various Thyroid Diseases "Our Experience at Tertiary Care Centre." International Journal of medical science and clinical inventions 2014;1(8):387-392.

16. Esmaili HA, Taghipour H. "Fine - Needle Aspiration in the Diagnosis of Thyroid Diseases: An Appraisal in Our Institution. International Scholarly Research Network Pathology. Volume 2012, Artical ID 912728.

17. Bagga PK, Mahajan NC. Fine needle aspiration cytology of thyroid swellings: How useful and accurate is it? Indian Journal of Cancer 2010;47:437-442.

18. Muratli A, Erdogan N, Sevim S, Unal I, Akyuz S. Diagnostic efficacy and importance of fine-needle aspiration cytology of thyroid nodules. J Cytol 2014;31:73-78.

19. Baruah RN, Zaman F. Cytomorphological diagnosis of thyroiditis and correlation with thyroid function. Thyroid Research and Practice.

20. Bhatta S, Makaju R, Mohammad A. Role of fine needle aspiration cytology in the diagnosis of thyroid lesions. Journal of Pathology of Nepal 2012;2:186-188.

21. Tabaqchali MA, et al. Thyroid aspiration cytology in Newcastle. Am R Coll surg Engl 2000;82:149-155.

22. Lakshmi S, Latha B, Nirmala C. Spectrum of thyroid lesions on fine needle aspiration cytology. Journal of International Medicine and Dentistry 2015;2(1):53-62.

23. Biogon M, Maoyer D. Solitary thyroid nodule. Postgraduate Medicine 1995;98:73-80.

24. Basharat R, Bukhari MH, Saeed S, Hamid T. Comparison of Fine Needle Aspiration Cytology and Thyroid Scan in Solitary Thyroid Nodule. Pathology Res Int. 2011;

25. Giuffrida D, Gharib H. Controversies in the management of cold, hot and occult thyroid nodules. Am J Med. 1995;99:642-650.

26. DeMicco, Zoro P, Garcia S, Skoog L, Tani EM, Carayon P. Thyroid peroxidise immunodetection as a tool to assist diagnosis of thyroid nodules on fine needle aspiration biopsy. Eur J Endocrinol 1994;131:474-479. 